\title{
Previous treatment with NOAC is associated with slower ultra-early intracranial hematoma growth compared with vitamin $\mathrm{K}$ antagonists
}

A. Brás ${ }^{1}$, J. Afonso Ribeiro1, C. Marques-Matos ${ }^{2,3}$, J. Nuno Alves ${ }^{4}$, J. Pedro Marto, ${ }^{5,6}$ A. Monteiro ${ }^{2,3}$, J. Araújo4, G. Santo1, F. Grenho7, M. Viana Baptista $^{5,6}$, J. Pinho4, E. Azevedo ${ }^{2,3}$, J. Sargento-Freitas ${ }^{1,8}$



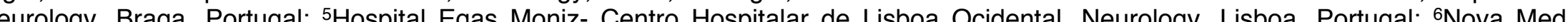

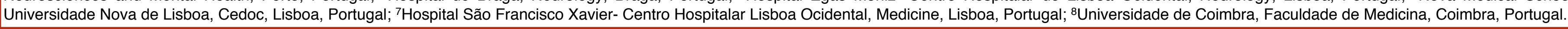

\section{BACKGROUND}

Ultra-early hematoma growth (UHG) estimates the initial hematoma expansion rate in acute non-traumatic intracranial hemorrhage $(\mathrm{ICH})$, representing a marker of its hemostatic properties.

Patients with ICH and oral anticoagulation are at particular risk of hematoma expansion, however the impact of different anticoagulants has not yet been fully ascertained.

\section{AIMS}

To compare UHG in patients on NOAC and vitamin $\mathrm{K}$ antagonists (VKA).

\section{METHODS}

Multicentre and retrospective cohort study;

A total of 131 patients were included with acute non-traumatic ICH on oral anticoagulation admitted during 30 -months period, with baseline $\mathrm{ICH}$ volume and time from symptom-onset to first CT-scan available for analysis;

Medical records were analysed for demographic, clinical, laboratory and imaging data;

UHG was defined as the relation between baseline ICH volume $(\mathrm{mL}) /$ time of symptom-onset to first CT-scan (hours), with volume obtained by planimetry (ITK-SNAP);

Univariate analysis (Pearson's chi-square/Fisher's exact test for categorical variables and Student's $t$-test/Mann-Whitney $U$ test for continuous variables) and propensity score matching (PSM) analysis (adjusted for age, elevated admission systolic BP and anticoagulation status) were performed;

Statistical significance $\mathrm{p}<0.05$

\section{RESULTS}

Of the 131 patients, $18(13.7 \%)$ were anticoagulated with a NOAC (11 on dabigatran and 7 on rivaroxaban) and $113(86.3 \%)$ with a VKA.

Characteristics of the cohort according to type of anticoagulant were demonstrated in the table. Values represent $\mathrm{n}(\%)$ or median (interquartile range).

\begin{tabular}{rrcr} 
& VKA $(\mathrm{n}=113)$ & NOAC $(\mathrm{n}=18)$ & $\boldsymbol{P}$ Value \\
\hline Age & & Demographic characteristics \\
\hline Female sex & $52(48.0-81.0)$ & $82.5(75.6-85.0)$ & 0.003 \\
& & $9(50 \%)$ & 0.753 \\
\hline Arterial hypertension & $99(87.6 \%)$ & $18(100 \%)$ & 0.215 \\
Diabetes mellitus & $27(23.9 \%)$ & $3(16.7 \%)$ & 0.763 \\
Dyslipidemia & $50(44.2 \%)$ & $7(38.9 \%)$ & 0.670 \\
Coronary heart disease & $8(7.1 \%)$ & $3(16.7 \%)$ & 0.177 \\
Cardiac failure & $21(18.8 \%)$ & $1(5.6 \%)$ & 0.307 \\
Mechanic heart valve & $9(8.0 \%)$ & $0(0.0 \%)$ & 0.610 \\
Peripheral artery disease & $1(0.9 \%)$ & $0(0.0 \%)$ & 0.863 \\
Excessive weight & $12(11.7 \%)$ & $2(11.1 \%)$ & 0.654 \\
Smoking & $7(6.7 \%)$ & $0(0.0 \%)$ & 0.592 \\
Previous hemorrhagic stroke & $3(2.7 \%)$ & $1(5.6 \%)$ & 0.450 \\
\hline Previous ischemic stroke & $20(17.7 \%)$ & $5(27.8 \%)$ & 0.337 \\
\hline
\end{tabular}

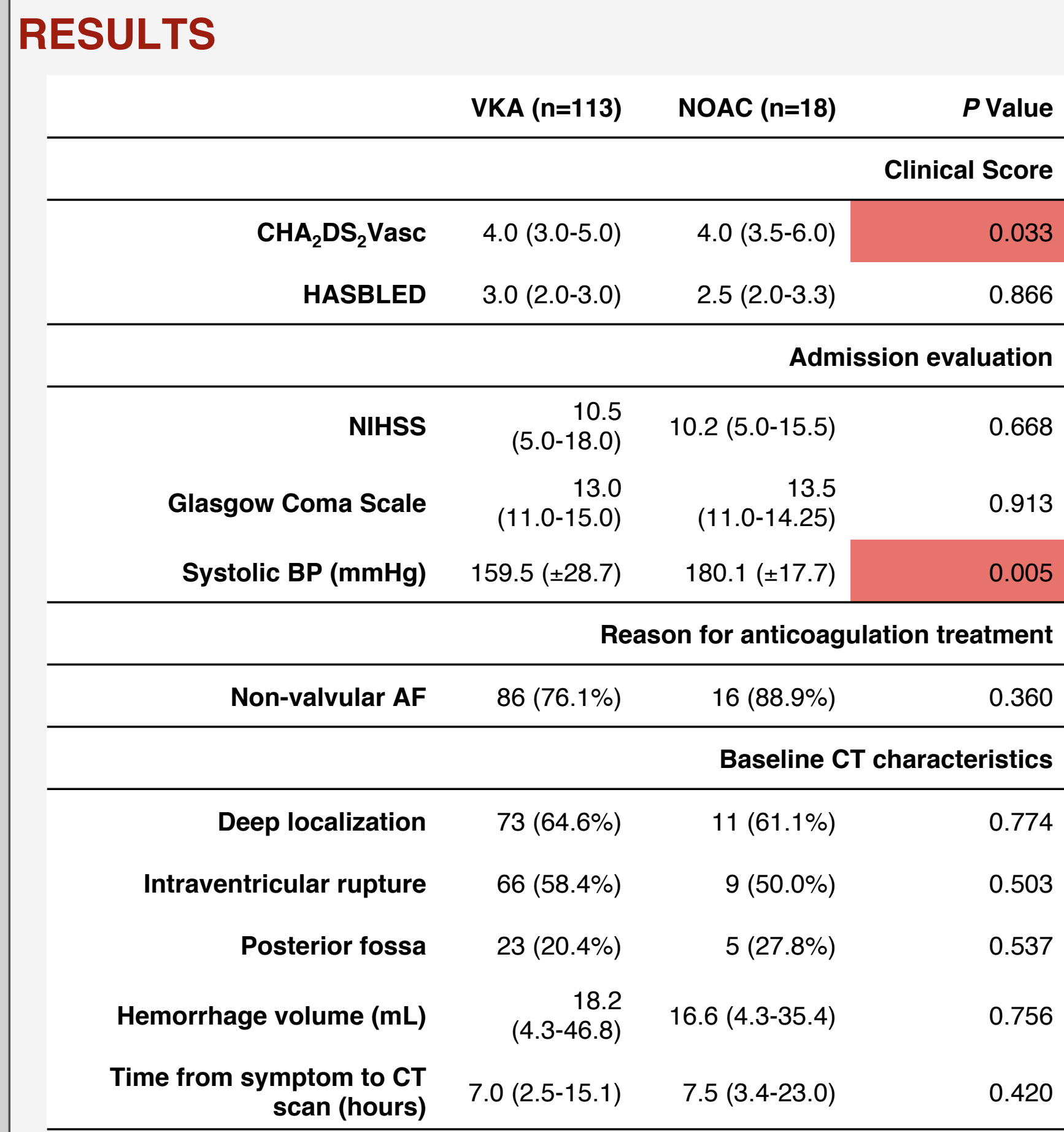

On univariate analysis:

Median UHG did not show significant differences (VKA $2.42 \mathrm{~mL} / \mathrm{h}$ vs. NOAC $1.93 \mathrm{~mL} / \mathrm{h}, \mathrm{p}=0.470$ ).

On PSM analysis (with a match in 18 NOAC- and 18 VKA-treated patients):

Median UHG* was higher in VKA-treated patients (VKA 5.73 $\mathrm{mL} / \mathrm{h}$ vs. NOAC $1.93 \mathrm{~mL} / \mathrm{h}$, $\left.{ }^{*} \mathrm{p}=0.026\right)$;

Hemorrhage volume was higher in VKA-treated patients (VKA $27.05 \mathrm{~mL}$ vs. NOAC $16.6 \mathrm{~mL}, \mathrm{p}=0.195$ )
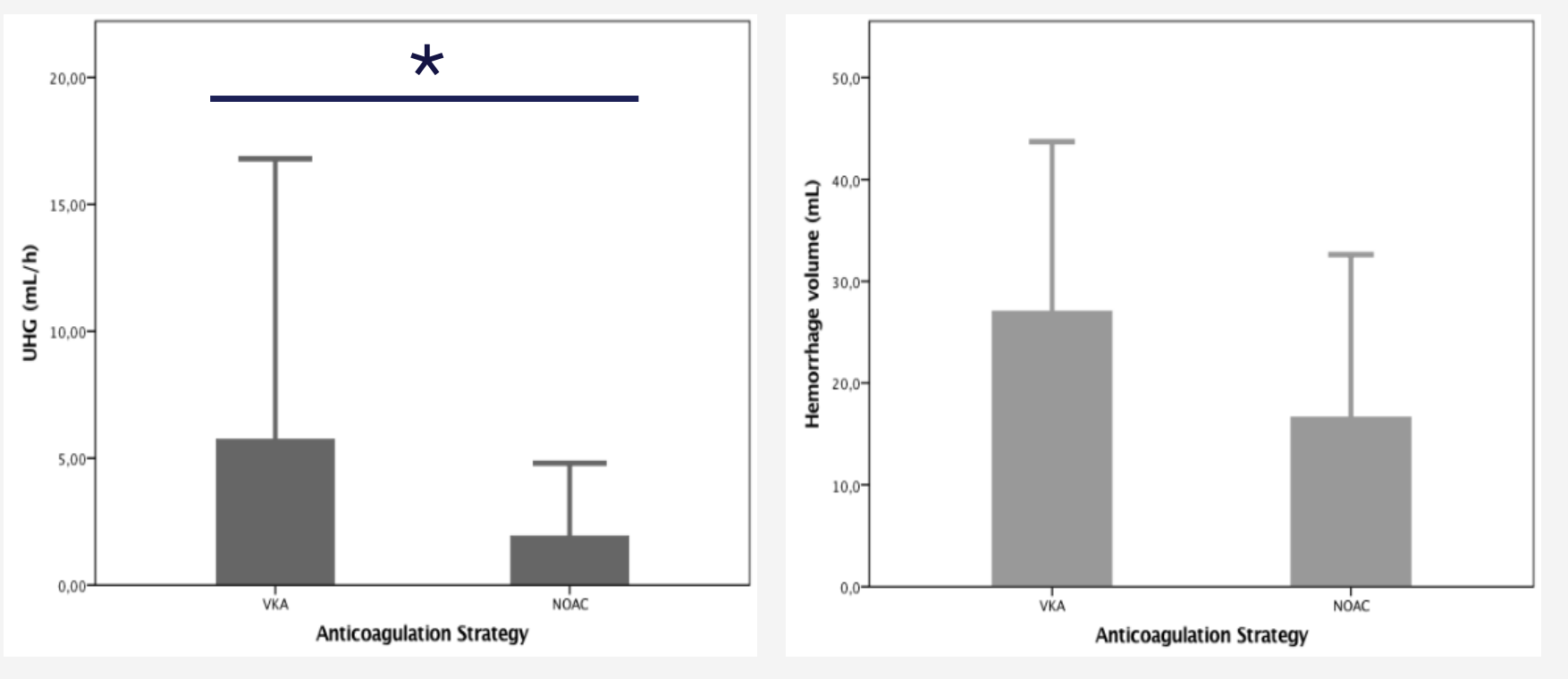

\section{CONCLUSION}

UHG in VKA- was higher when compared to NOAC-treated patients using matching statistics (when considering groups with similar age and admission systolic BP).

Our study suggests that NOAC-treated patients may have an initial slower rate of hematoma expansion comparing to VKA-treated patients.

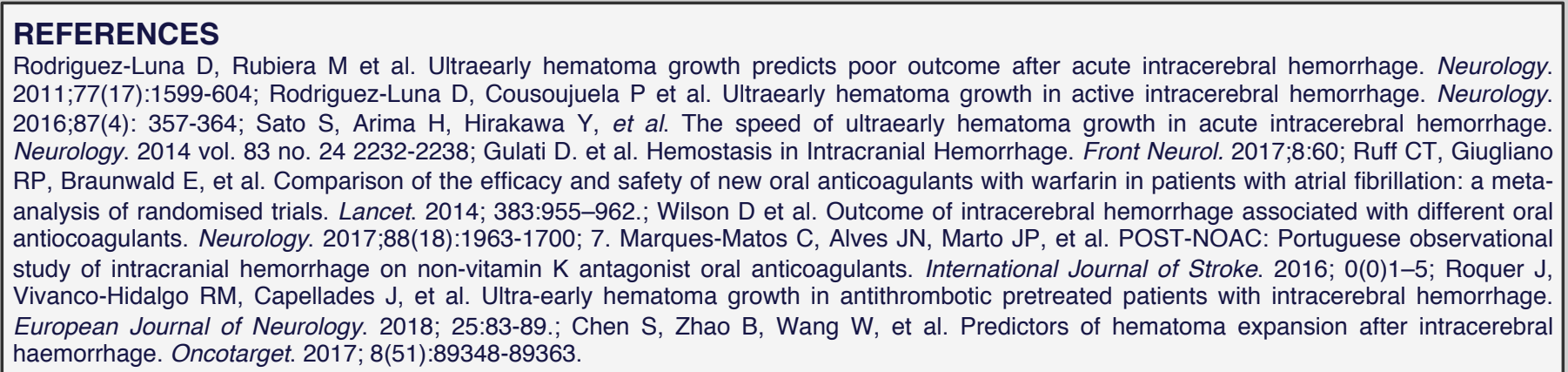

